\title{
THE USE OF TRAJECTORY CLUSTER ANALYSIS TO EXAMINE THE LONG-RANGE TRANSPORT OF SECONDARY INORGANIC AEROSOL IN THE UK
}

Salah Abdulmogith and Roy M. Harrison*

Division of Environmental Health \& Risk Management School of Geography, Earth \& Environmental Sciences

The University of Birmingham

Edgbaston, Birmingham B15 2TT

United Kingdom 


\section{ABSTRACT}

The influence of synoptic-scale atmospheric transport patterns on observed levels of sulphate, nitrate and $\mathrm{PM}_{10}$ at Belfast (urban) and Harwell (rural) has been examined. Three-day 6-hourly back trajectories for January 2002 to December 2003, arriving at the two sampling locations at 1200 GMT and $950 \mathrm{hPa}$ were calculated. A k-means clustering algorithm is used to group these trajectories into 10 clusters depending on their direction and speed. Non-parametric statistics were used to test for significant differences in mean aerosol concentration across clusters. Significant inter-cluster differences were observed with highest nitrate and sulphate levels associated with south-easterly and easterly trajectory clusters at Belfast and Harwell respectively, and highest chloride concentrations associated with fast moving maritime trajectory categories at both sites. Easterly trajectory clusters show lower sulphate/nitrate ratios compared to other clusters, especially for air travelling from the near continent,. Nitrate shows greater episodicity than sulphate with implications for achievement of the daily $\mathrm{PM}_{10}$ limit value of $50 \mu \mathrm{g} \mathrm{m}^{-3}$. Our trajectory analysis suggests that control of $\mathrm{NO}_{\mathrm{x}}$ emissions from the UK and adjacent continental European countries has a major role to play in achieving compliance with the current $\mathrm{PM}_{10}$ limit value.

Keywords: Back trajectory; clustering; sulphate, nitrate, chloride 


\section{INTRODUCTION}

Trajectories are defined as the paths of infinitesimally small particles of air (Dutton, 1986). While forward trajectories describe where a particle will go, backward trajectories indicate where it came from. Air trajectories are frequently used for interpretation of individual flow situations for several decades, but statistical methods for large sets of trajectories have been developed more recently. Cluster analysis is a multivariate statistical technique increasingly used in air pollution research. This method involves splitting the data set into a number of groups which need to be as homogenous and as distinctly different from each other as possible. Generally, the result of application of the cluster analysis technique to air trajectories is similar to a flow climatology in which trajectories are classified into groups according to certain criteria, but cluster analysis is more objective, and it accounts for variation in transport speed and direction simultaneously, yielding clusters of trajectories which have similar length and curvature (Moody and Samson, 1989; Harris and Kahl, 1990). The accuracy and limitations of trajectory calculations have been investigated by several researchers (Stohl, 1998; Stunder, 1996; and Kahl, 1996). The authors concluded that the accuracy of an individual trajectory is ultimately limited by temporal and spatial resolution of meteorological observations, measurement errors, analysis errors and by any simplifying assumptions used in the trajectory model. Moody and Galloway (1988) were the first to consider trajectory coordinates as the clustering variables. Aerosol data have been analysed based on air mass trajectories (Kemp, 1993; Mukai and Suzuki, 1996). Brankov et al. (1998) presented a trajectory clustering methodology for interpreting a 5-yr time-series data of ozone concentrations at Whiteface Mountain, United States. Cape et al., (2000) used cluster analysis to interpret ozone concentrations measured at Mace Head, Ireland, and found clear differences among the trajectories for the measured ozone concentration. Buchanan et al., (2002) applied the cluster analysis technique to investigate long-range transport of airborne particle concentrations in Edinburgh, Scotland.

Dutkiewics, et al., (2004) used air trajectories to estimate the long-range transport of sulphate at three sites in New York State; based on annual average the authors predicted an import of 44-55\% at the urban Queens and 60\% at the rural Whiteface and Pinnacle sites. In the study reported here, 
aerosol component concentrations were measured over a period of two years (2002-2003), and back trajectories were calculated using the HYSPLIT_4 online service. Air trajectory data were assigned to clusters according to their speed and direction using a clustering algorithm. The data were also split into four seasons and cluster analysis was applied to assess seasonal variation. Then the Kruskal-Wallis test was used to test the significance of inter-cluster variation in aerosol concentration.

\section{METHODOLOGY}

\section{Air Quality Measurements}

Particulate matter $\left(\mathrm{PM}_{10}\right)$ samples have been collected using Partisol samplers at two sampling locations, Belfast (urban) and Harwell (rural). The Belfast monitoring station is within a selfcontained, air conditioned housing located in a pedestrianised area in Belfast city centre, largely enclosed by high buildings. In contrast, the Harwell site is located within the grounds of the Harwell Science Centre, Didcot, Oxfordshire, and surrounded by predominantly agricultural land. Daily samples were collected from the sites at Belfast and Harwell for chemical analysis. These sites form part of the DEFRA Automatic Urban and Rural Monitoring Network (AURN). The Partisol Model 2025 Sequential Air Sampler was used throughout the sampling period at both sites. The instrument has an air flow of $16.71 \mathrm{dm}^{3} \mathrm{~min}^{-1}$ through a $\mathrm{PM}_{10}$ inlet and is designed to allow uninterrupted sampling of ambient air and automatic exchange of filters for up to 16 consecutive days. The $\mathrm{PM}_{10}$ samples were collected upon a $47 \mathrm{~mm} 1 \mu \mathrm{m}$ size PTFE filter medium. Data on $\mathrm{PM}_{10}$ mass concentration were obtained from the National Air Quality Information Archive at the AEA Technology National Environmental Technology Centre website (http://www.aeat.co.uk/netcen/airqual). The data were measured by Tapered Element Oscillating Microbalance (TEOM) and are therefore subject to loss of semi-volatile constituents, as reported by Charron et al. (2004).

A 1000 ppm mixed standard solution containing sodium chloride, sodium nitrate and ammonium sulphate was prepared and stored in a polypropylene bottle in the cold room $\left(4^{\circ} \mathrm{C}\right)$. 
Fresh 1000 ppm standard solution was prepared every six months. Diluted standard solutions in the range of $0.05 \mathrm{ppm}$ to $10 \mathrm{ppm}$ were prepared weekly using the $1000 \mathrm{ppm}$ solution and DDW.

Exposed air filters were stored at $4^{\circ} \mathrm{C}$ in sealed polythene bags and prior to analysis were transferred from their filter bags to polypropylene bottles and $0.5 \mathrm{ml}$ propan-2-ol was added to each sample. Then, $10 \mathrm{ml}$ of DDW were added and the bottles were loaded onto a mechanical shaker for 20 minutes to ensure through extraction of the water-soluble aerosols.

The filter extracts were analysed for chloride, nitrate and sulphate using ion chromatography on a Dionex DX-500 ion chromatograph. A GP40 gradient pump was used to deliver eluent to the system. A 1ml sample loop was loaded via an AS40 Automated Sampler, using polyVials (5 ml) and plain caps. Detection was via CD20 Conductivity Detector at an output range of $10 \mu \mathrm{S}$. The analytical column used was an Ion Pac AS11 (2x 250 mm) and a guard column AG11 (2x250 mm). Conductivity was suppressed with a Dionex ASRS II suppressor in the recycle mode. The eluent used in most of the analysis was the manually prepared sodium hydroxide but recently the system was equipped with an EG40 electrolytic eluent generator coupled with a potassium hydroxide eluent cartridge. A personal computer equipped with Dionex PeakNet 5.1 software was used for instrument control, data collection and data processing. Analytical performance and absence of interferents were evaluated by analysing an extracted solution of blank filters, standard solutions, and samples spiked with known sulphate, nitrate and chloride concentrations.

\section{Trajectories Calculation and Clustering}

Backward air trajectories arriving at our observation sites were calculated using the Web version of the Hybrid Single Particle Lagrangian Integrated Trajectory (HYSPLIT-4) model. This model is a system for computing air mass trajectories and complex dispersion and deposition simulations (Draxler and Hess, 1997, 1998). Meteorological data fields to run the model are available from routine archives or from forecast model outputs. In this study, we calculated threeday back trajectories using the National Weather Service's National Centers for Environmental Prediction (NCEP) model data available in NOAA's Air Resources Laboratory (ARL) archives. 
The 6-hourly FNL archived data for the northern hemisphere come from the final run in the series of NCEP operational runs, it is therefore known as the Final (FNL) Run at NCEP and includes late arriving conventional and satellite data. It is run 4 times a day, i.e., at $00,06,12$, and 18 UTC. A fixed value of $950 \mathrm{hPa}$ was used as the arrival level. For each day four 6-hourly trajectories with ending time of $0000,0600,1200$, and 1800 were calculated. In order to control for self-consistency within the daily trajectory group, the four 6-hourly trajectories were plotted for each day. Groups of four 6-hourly trajectories in which individual trajectories were found to have substantially different origin or/and follow different paths were excluded from the analysis. Trajectories were rejected or excluded from the analysis only when at least two of the four 6-hourly trajectories originated from continental areas or passed over a continental area before their arrival at the sampling locations while the other two trajectories were originated from maritime areas and hadn't passed over any polluted areas; otherwise they were included. Then, trajectories arriving at 1200 GMT at Harwell and Belfast, the midpoint of the sampling time used to collect air pollution data, were analysed. Each measured pollutant concentration was associated with its corresponding $72 \mathrm{~h}$ back trajectory arriving (ending) at each site. The choice of the $72-\mathrm{h}$ back trajectory length is supported by the lifetime of the different secondary species, (Wojcik and Chang, 1997). For each 3day $(72 \mathrm{~h})$ trajectory, $72 \mathrm{x}-\mathrm{y}$ coordinates (i.e. end points of the trajectory location at every hour) are utilised as input variables for the clustering algorithm. Errors associated with a single trajectory are reduced when daily trajectories are categorised according to the common path air parcels followed (Stohl, 1998; Brankov et al., 1998). Therefore, 587 and 483 daily midday back trajectories arriving at Belfast and Harwell respectively were assigned to ten clusters using an automated k-means clustering algorithm. In this algorithm, distances between trajectories were computed using simple Euclidean distance as follows:

Distance $(x, y)=\sum g_{i} \cdot \sum f_{i}(k) \cdot\left(x_{i k}-y_{i k}\right)^{p}$

Where $p=2$ (Euclidean distance), the variables included are trajectory longitude and trajectory latitude, with $i=2$, weights $g_{i}$ were assigned to each variable to adjust for different units. 
The average back trajectory of each cluster is then calculated from its trajectory members. The average back trajectories for 10 clusters at Belfast and Harwell are presented in Figures 1 and 2. The effects of weather related variations on the pollutant transport were taken into account when using trajectory cluster analysis. Accordingly, the data set was split into four seasons: JanuaryMarch, April-June, July-September, and October-December. The clustering algorithm is used to group individual back trajectories of each season into five clusters.

The trajectory and pollution data discussed below represent only $79 \%$ and $65 \%$ the total 2 years data for Belfast and Harwell respectively. Generally, the missing data were the result of equipment malfunction or non-compliance of data with the trajectory matching criteria discussed in section 2.2. which leads to the exclusion of both concentration and trajectory data. The data capture was $89 \%$ and $76 \%$ at Belfast and Harwell respectively. Whereas the data excluded due its noncompliance with the trajectory matching criteria were $10 \%$ and $11 \%$ for Belfast and Harwell respectively. A greater proportion of the missing data at Harwell were during the period from January to March 2003 and mainly due equipment malfunction.

\section{RESULTS}

\section{Whole Data Set 2002-2003}

The clustering results at Belfast (Figure 1) and Harwell (Figure 2) are very similar, despite the existence of two short-range clusters (easterly and westerly) in Harwell and not in Belfast. The main trajectory clusters presented above compare very well with those defined by Cape, et al., (2000), although our cluster analysis yielded a pair of fast and slow flow clusters on each direction rather than one cluster. The mean trajectory paths for the whole data set for 2002-2003 are shown in Figure 3. The westerly air flow arriving at both sites is the most frequent at both sites, with $31 \%$ at Belfast and $47 \%$ at Harwell in this class. The highest chloride concentrations were observed for Belfast. Trajectory class mean chloride concentrations ranged from $1.27 \mu \mathrm{g} \mathrm{m}^{-3}$ to $2.82 \mu \mathrm{g} \mathrm{m}^{-3}$ at Belfast, and from $0.31 \mu \mathrm{g} \mathrm{m}^{-3}$ to $2.23 \mu \mathrm{g} \mathrm{m}^{-3}$ at Harwell (Table 1). The highest chloride concentrations at Belfast were associated with the fastest maritime air flow (clusters 3, 4, and 9), 
whilst the continental air masses make the lowest contribution to chloride concentration at Belfast (clusters, 6, 7, and 8) (Figure 2; Table 1). The highest chloride concentrations were strongly associated with the fastest maritime air flow (cluster 3), whereas, very slow marine air flow (cluster 5) and air originated from western Europe (cluster 7) have the lowest chloride concentrations measured at Harwell (Figures 2 and 3; Table 1).

Table 1 contains the mean chloride, nitrate, sulphate, $\mathrm{PM}_{10}$, and the ratio between sulphate and nitrate concentrations for all trajectory clusters arriving at Belfast. The mean concentrations associated with these clusters ranged from 0.89 to $6.81 \mu \mathrm{g} \mathrm{m}^{-3}, 0.98$ to $4.37 \mu \mathrm{g} \mathrm{m}^{-3}$ and 12.82 to $26.91 \mu \mathrm{g} \mathrm{m}^{-3}$ for nitrate, sulphate, and $\mathrm{PM}_{10}$ respectively. The mean nitrate concentration of the back trajectory cluster with highest concentration was $4.35 \mu \mathrm{g} \mathrm{m}^{-3}$ higher than the mean nitrate concentration for the whole dataset, whilst the mean sulphate concentration of the back trajectory cluster associated with the highest concentration is only $2.35 \mu \mathrm{g} \mathrm{m}^{-3}$ higher than the mean sulphate concentration for the whole dataset. The highest and lowest nitrate concentrations at Belfast were associated with cluster 6 (southeast) and cluster 3 (maritime) respectively (Table 1), whereas the highest and lowest sulphate concentrations were associated with cluster 8 and cluster 9 respectively (Table 1). Relatively higher nitrate and sulphate concentrations associated with continental flows (clusters 6, 8, and 7 respectively) indicate that the urban and industrial European source regions to the southeast, east and northeast, of both Belfast and Harwell contribute to aerosol concentrations measured at these sites. These results are consistent with earlier work. Buchanan et al. (2002) have shown that $\mathrm{PM}_{10}$ concentrations associated with Eastern European back trajectories are significantly higher than those associated with other trajectory categories. Malcolm et al. (2000) used dispersion modelling to investigate trans-boundary transport of particulate pollution in the UK and concluded that the concentrations are highest when air parcels pass over the European source regions en route to the UK. Whilst Belfast is an urban site, our analysis is based on the premise that the oxidation rates of sulphur and nitrogen oxides are insufficient for local formation of sulphate and nitrate to influence the measured concentrations appreciably. The European aerosol phenomenology report (Putaud et al., 2004) suggests a possible urban increment for nitrate, but not on the basis of 
conclusive data or even measurements from proximate urban and rural sites. The fact that similar phenomena appear to influence concentrations in both urban Belfast and rural Harwell suggests that an urban effect is at most very small. The $\mathrm{PM}_{10}$ mass concentrations are, as expected, affected by local primary emissions at Belfast, although the influence of air mass back trajectory is also significant (Table 1).

Table 1 also shows the mean sulphate, nitrate, chloride, and sulphate/nitrate ratio concentrations for trajectory clusters for Harwell. The mean concentrations associated with these clusters ranged from 1.35 to $9.02 \mu \mathrm{g} \mathrm{m}^{-3}, 1.30$ to $4.89 \mu \mathrm{g} \mathrm{m}^{-3}$ and 10.21 to $23.14 \mu \mathrm{g} \mathrm{m}^{-3}$ for nitrate, sulphate and $\mathrm{PM}_{10}$ respectively. As for Belfast, the continental air masses were found to have the highest nitrate, sulphate and $\mathrm{PM}_{10}$ concentrations measured at Harwell. Clusters 7 and 8 for Harwell show a massive elevation in both sulphate and nitrate relative to other trajectories. These findings are consistent with earlier work. Malcolm et al. (2000) identified that concentrations of particulate pollution are highest when air parcels pass over European source regions en route to the UK. Dutkiewicz et al. (2004) assigned back trajectories arriving at three sampling locations in New York state to 12 sectors, the results indicating that the westerly air flow (air passed over the $\mathrm{SO}_{2}$ emission region in the industrial Midwest) were associated with the highest sulphate concentrations during both the cold and the warm period. At Harwell, the fast moving maritime air masses (clusters 3 and 4) have the lowest contribution to the measured nitrate, sulphate and $\mathrm{PM}_{10}$ concentrations (Figure 2; Table 1). Northerly air passing over the UK before arriving at Harwell (Figure 2) is associated with intermediate nitrate and sulphate concentration (clusters 9, and 10), as is the slow-moving marine flow with a long transport time over the UK or European source regions to the south of Harwell (clusters 6 and 5 respectively).

Ratios of sulphate/nitrate vary by a factor of more than two according to trajectory (Table 1). The lowest ratios (cluster 6 at Belfast and cluster 7 at Harwell) are associated with slow-moving continental air, possibly reflecting the high $\mathrm{NO}_{\mathrm{x}} / \mathrm{SO}_{2}$ emissions ratios typical of western Europe. Cluster 8 at Harwell which has a larger input from eastern European sources has an appreciably higher $\mathrm{SO}_{4}{ }^{2-} / \mathrm{NO}_{3}{ }^{-}$ratio than cluster 7 . The highest $\mathrm{SO}_{4}{ }^{2-} / \mathrm{NO}_{3}{ }^{-}$ratios are generally associated with 
maritime trajectories and low sulphate and nitrate concentrations. This may be explicable in terms of the expected longer lifetime of accumulation mode sulphate than nitrate, often in the coarse mode in maritime air (Huang et al., 2004). The ratios are also consistent with different prevailing chemical processes in low- and high-NO $\mathrm{NO}_{\mathrm{x}}$ photochemical regimes (Stein and Lamb, 2003).

Highest mean nitrate, sulphate and $\mathrm{PM}_{10}$ concentrations were observed for south-easterly (cluster 6) and easterly (cluster 8) trajectory categories respectively at Belfast, whilst the highest mean nitrate, $\mathrm{PM}_{10}$, and sulphate concentrations were associated with easterly air flows (clusters 7 and 8 respectively) at Harwell. At both sites, the lowest nitrate, sulphate and $\mathrm{PM}_{10}$ mean concentrations were mainly associated with fast moving maritime air masses (clusters 3, 4, and 9). Seasonal disaggregation of data showed that for both Belfast and Harwell, the highest concentrations of nitrate and sulphate were observed in the spring, whilst the highest mean concentration of $\mathrm{PM}_{10}$ was seen in the winter and the spring in Belfast and Harwell respectively (Figure 5; Tables 2 and 3). In the case of Belfast, local urban primary emissions may be important. Kruskal-Wallis non-parametric tests indicate significant differences $(\rho<<<0.05)$ in aerosol concentrations among clusters arriving at both sampling locations. Pair-wise comparisons of chloride, nitrate, sulphate, and $\mathrm{PM}_{10}$ concentrations by cluster using Tukey's student t-test were performed. Overall, the results show that chloride mean concentrations associated with fast moving maritime air masses (cluster 3) are significantly higher compared to those associated with relatively slow moving maritime (cluster 1, 2, 4, 5, 9, and 10), and continental air masses ( cluster 5, 6, 7, and 8) at the two sampling locations. Similarly, nitrate, sulphate and $\mathrm{PM}_{10}$ concentrations associated with continental trajectory categories (cluster 6, 7, and 8) are significantly higher than pollutant concentrations observed for other trajectory categories.

\section{Individually Analysed Years}

Separate analyses were made for each of the two years (2002 and 2003) and the mean trajectory paths and the frequency distribution results are presented in Figures 3 and 4 respectively. The overall pattern of clusters is similar for the two years (2002 and 2003) at both sites. The 2002 
clusters are very similar to those obtained using the whole data set (2002-2003). At Belfast, the NE cluster moved further north and as a result we have three clusters with fast, slow and very slow flows to the north of Belfast in 2003. A new western European cluster (easterly) with slow moving air flow is seen in 2003 at Harwell. The proportion of the westerly flow at Harwell (westerly and south-westerly) is relatively greater for 2002 compared to 2003, whereas, an approximately similar proportion of westerly (westerly and south-westerly) flows were observed for each of the two years at Belfast. The annual mean nitrate aerosol concentration during the years 2002 and 2003 was 1.70 $\mu \mathrm{g} \mathrm{m}^{-3}$ and $3.22 \mu \mathrm{g} \mathrm{m}^{-3}$ respectively, in Belfast, and $2.83 \mu \mathrm{g} \mathrm{m}^{-3}$ and $3.75 \mu \mathrm{g} \mathrm{m}^{-3}$ respectively in Harwell. The main explanation for the difference in the annual mean nitrate aerosol concentration is that the total proportion of northerly (clusters 9 and 10), easterly (clusters 7 and 8 ) and south or south-easterly (clusters 5 and 6) flow was greater for 2003 than 2002.

\section{Seasonal Variation}

If the pollution data extend over a period of several years, it is necessary to separate the shortterm component from seasonal and long-term components of the time series (Rao et al., 1997). Previous cluster analysis studies have split whole data sets into seasons in order to investigate seasonal patterns (e.g. Brankov, et al., 1998; Cape, et al., 2000). Therefore, the 2-year data set was split into four seasons, winter (January-February and December), spring (March-May), summer (June-August) and autumn (September-November) and the cluster analysis technique was applied to each of the four seasons separately. A similar pattern was seen for each season at the two sites, although some minor differences exist (Figure 5). For both sites, the mean direction of the northwesterly cluster has moved further north in the winter. In the summer the easterly flow is represented by a short -range trajectory cluster. The easterly flow is more common during autumn (23\%) in Belfast and spring and summer (20\% each) in Harwell respectively, whereas, westerly flow is more frequent during winter (35\%) in Belfast and during spring and winter (35\% and 31\% respectively) in Harwell (frequency data not shown). Our findings are not directly comparable to those of previous studies (Merrill, 1994; Cape et al., 2000) because we adopted different definitions 
for seasons than those used in these studies. The proportion of northerly flow remains almost constant throughout the year at both sites, whereas the proportion of south-westerly trajectories at the two sampling locations is greater during the winter. The highest chloride concentration was observed in the winter and mainly associated with fast maritime air mass trajectories (cluster 2). At both sites, the highest nitrate, sulphate and $\mathrm{PM}_{10}$ concentrations observed for all seasons were associated with easterly air flow (cluster 4). Overall, relatively lower concentrations were observed during autumn and summer than during spring and winter. The highest nitrate and sulphate concentrations at our two sampling locations were observed in spring, whilst the highest $\mathrm{PM}_{10}$ concentrations were observed during winter and spring for Belfast and Harwell respectively.

\section{CONCLUSIONS}

The largest daily contributions to annual mean $\mathrm{PM}_{10}$ concentration were observed for the continental clusters (clusters 8, 6, and 7 respectively) at Belfast (Table 4). At Harwell, the easterly clusters (cluster 8 and 7) are the major daily contributors to annual mean $\mathrm{PM}_{10}$ concentration respectively (Table 4). The European Union Daughter Directive has set an objective that the annual mean $\mathrm{PM}_{10}$ concentration should not exceed $40 \mu \mathrm{g} \mathrm{m} \mathrm{m}^{-3}$ and the 24-hour mean $\mathrm{PM}_{10}$ concentration should not exceed $50 \mu \mathrm{g} \mathrm{m}^{-3}$ more than 35 times a year by 2005 . The $40 \mu \mathrm{g} \mathrm{m}^{-3}$ limit value has not been exceeded at all during the study period (2002-2003). The $50 \mu \mathrm{g} \mathrm{m}^{-3} 24$-hour mean concentration limit value was exceeded only 3 times at Harwell during 2003, two of them associated with easterly clusters (cluster 7 and 8), and not exceeded at all during 2002. Whilst the $50 \mu \mathrm{g} \mathrm{m}^{-3}$ daily limit value was exceeded 3 times and 4 times during 2002 and 2003 respectively in Belfast, 6 of the 7 times were associated with continental clusters ( cluster 6,7 , and 8). Abatement measures at the European level are of great importance since trajectory clusters which pass over Europe prior to their arrival at Belfast and Harwell are associated with the highest $\mathrm{PM}_{10}$ mean concentrations. As the control of primary pollutants serves to reduce $\mathrm{PM}_{10}$ concentration, so the influence of secondary constituents will become more marked. The data in Table 4 are strongly indicative of both a greater contribution of nitrate than sulphate to annual mean $\mathrm{PM}_{10}$, and more 
importantly in relation to the daily limit value, a far greater episodicity of nitrate than sulphate as indicated by the ratio of $90 \%$ ile to $10 \%$ ile concentrations. Our earlier work (Harrison et al., 2004 has demonstrated the important role of nitrate in causing exceedence of the daily $\mathrm{PM}_{10}$ limit value. This, together with the trajectory analyses, suggests that control of $\mathrm{NO}_{\mathrm{x}}$ emissions in the $\mathrm{UK}$ and adjacent western European countries may have a major role to play in achieving daily concentrations within the $50 \mu \mathrm{g} \mathrm{m}^{-3}$ limit.

\section{ACKNOWLEDGEMENT}

This project is funded by the Department for the Environment, Food and Rural Affairs (Contract No. EPG 1/3/184). Trajectory data were obtained from the HYSPLIT-4 on-line services. The clustering algorithm was developed by Dr Wolfram Birmili.

\section{REFERENCES}

Buchanan, C. M., Beverland, I. J. and Heal, M. R., 2002. The influence of weather-type and longrange transport on air particle concentrations in Edinburgh, UK. Atmospheric Environment 36, 5343-5354.

Brankov, E., Rao, S. T. and Porter, P. S., 1998. A Trajectory-Clustering-Correlation Methodology for Examining the Long-Range Transport of Air Pollutants. Atmospheric Environment 32, 15251534.

Cape, J. N., Methven, J. and Hudson, L. E., 2000. The use of trajectory cluster analysis to interpret trace gas measurements at Mace Head, Ireland. Atmospheric Environment 34, 3651-3663.

Charron, A., Harrison, R.M., Moorcroft, S. and Booker, J., 2004. Quantitative interpretation of divergence between $\mathrm{PM}_{10}$ and $\mathrm{PM}_{2.5}$ mass measurements by TEOM and gravimetric (Partisol) instruments. Atmospheric Environment 38, 415-423.

Dutkiewics, V. A., Qureshi, S., Khan, A. R., Ferraro, V., Schwab, J., Demerjian, K., Husain, L., 2004. Sources of fine particulate sulphate in New York. Atmospheric Environment 38, 31793189.

Draxler, R. R., and Hess, G. D., 1997. Description of the HYSPLIT_4 modelling system. NOAA Technical Memorandum ERL ARL-224, December, 24pp.

Draxler, R. R., and Hess, G. D., 1998. An overview of the HYSPLIT 4 modelling system for trajectories, dispersion and deposition. Australian Meteorological Magazine 47, 295-308.

Dutton, J. A., 1986. The Ceaseless Wind. An Introduction to the Theory of Atmospheric Motion. Dover, New York.

Harris, J.M. and Kahl, J.D., 1990. A descriptive atmospheric transport climatology for the Mauna Loa Observatory, using clustered trajectories. Journal of Geophysical Research 95, 13651-13667.

Harrison, R.M., Jones, A.M. and Lawrence, R.G., 2004. Major component composition of PM 10 and $\mathrm{PM}_{2.5}$ from roadside and urban background sites, Atmospheric Environment 38, 4531-4538.

Huang, Z., Harrison, R.M., Allen, A.G., James, J.D., Tilling, R.M. and Yin, J., 2004 . Field intercomparison of filter pack and impactor sampling for aerosol nitrate, ammonium, and sulphate at aoastal and inland sites. Atmospheric Research 71, 215-232.

Kahl, J. D. W., 1996. On the prediction of trajectory model error. Atmospheric Environment 30, 2945-2957. 
Kemp, K., 1993. A multi-point receptor model for long-range transport over southern Scandinavia. Atmospheric Environment 27A, 823-830.

Malcolm, A.L., Derwent, R.G., and Maryon, R.H., 2000. Modelling the long-range transport of secondary $\mathrm{PM}_{10}$ to the UK. Atmospheric Environment 34, 881-894.

Merrill, J. T., 1994. Isentropic airflow probability analysis. Journal of Geophysical Research 99, 25881-25889.

Moody, J.L. and Galloway, J.N., 1988. Quantifying the relationship between atmospheric transport and the chemical composition of precipitation on Bermuda. Tellus 40B, 463-479.

Moody, J.L. and Samson, P.J., 1989. The influence of atmospheric transport on precipitation chemistry at two sites in the Midwestern United States. Atmospheric Environment 23, 2117-2132.

Mukai, H., and Suzuki, M., 1996. Using air trajectories to analyse the seasonal variation of aerosols transported to the Oki islands. Atmospheric Environment 30, 3917-3934.

Putaud, J.-P., Raes, F., Van Dingenen, R., Brüggermann, E., Facchini, M.-C., Decesari, S., Fuzzi, S., Gehrig, R., Hüglin, C., Laj, P., Lorbeer, G., Maenhaut, W., Mihalopoulos, N., Müller, K., Querol, X., Rodriguez, S., Schneider, J., Spindler, G., ten Brink, H., Tøseth, K. and Wiedensohler, A., 2004. A European aerosol phenomenology-2. chemical characteristics of particulte matter at kerbside, urban, rural and background sites in Europe, Atmospheric Environment 38, 2579-2595.

Rao, S. T., Zurbenko, I. G., Neagu, R., Porter, P. S., Henry, R. F. and Ku, J. Y., 1997. Space and time scales in ambient ozone data. Bulletin of American Meteorological Society 78(10), 21532166.

Stein, A.F. and Lamb, D., 2003. Empirical evidence for the low- and high-NO $\mathrm{NO}_{\mathrm{x}}$ photochemical regimes of sulfate and nitrate formation, Atmospheric Environment 37, 3615-3625.

Stohl, A., 1998. Computation, accuracy and applications of trajectories-a review and bibliography. Atmospheric Environment 32, 947-966.

Stunder, B. J. B., 1996. An assessment of the quality of forecast trajectories. Journal of Applied Meteorology 35, 1319-1331.

Wojcik, G.S. and Chang, J.S., 1997. Chang, a re-evaluation of sulphur budgets, lifetimes, and scavenging ratios for eastern north America. Journal of Atmospheric Chemistry 26, 109-145.

Mukai, H., and Suzuki, M., 1996. Using air trajectories to analyse the seasonal variation of aerosols transported to the Oki islands. Atmospheric Environment 30, 3917-3934. 
Table 1: Mean chloride, nitrate, sulphate, and $\mathrm{PM}_{10}$ concentrations by trajectory cluster for 2002-2003 at Belfast and Harwell, in $\mu \mathrm{g} \mathrm{m}^{-3}$

\begin{tabular}{lllllll|lllll}
\hline \multicolumn{1}{c|}{ Belfast } & & & & & \\
Aarwell & & & \\
Aerosol & $\mathrm{N}$ & $\mathrm{Cl}$ & $\mathrm{NO}_{3}$ & $\mathrm{SO}_{4}$ & $\mathrm{SO}_{4} / \mathrm{NO}_{3}$ & $\mathrm{PM}_{10}$ & $\mathrm{Cl}$ & $\mathrm{NO}_{3}$ & $\mathrm{SO}_{4}$ & $\mathrm{SO}_{4} / \mathrm{NO}_{3}$ & $\mathrm{PM}_{10}$ \\
\hline Cluster 1 & $93 / 34$ & 1.62 & 1.52 & 1.54 & 1.01 & 14.53 & 1.06 & 1.35 & 1.45 & 1.07 & 10.21 \\
Cluster 2 & $103 / 90$ & 1.84 & 1.60 & 1.52 & 0.95 & 14.83 & 1.01 & 1.90 & 1.78 & 0.94 & 11.38 \\
Cluster 3 & $75 / 60$ & 2.82 & 0.89 & 1.19 & 1.33 & 15.89 & 2.23 & 1.39 & 1.30 & 0.94 & 10.77 \\
Cluster 4 & $60 / 57$ & 2.18 & 1.19 & 1.53 & 1.28 & 12.82 & 0.97 & 1.65 & 1.71 & 1.04 & 11.02 \\
Cluster 5 & $69 / 30$ & 1.60 & 1.85 & 1.85 & 1.00 & 13.77 & 0.81 & 4.37 & 2.58 & 0.59 & 15.77 \\
Cluster 6 & $50 / 68$ & 1.27 & 6.81 & 3.74 & 0.55 & 25.28 & 0.31 & 3.10 & 2.74 & 0.88 & 14.71 \\
Cluster 7 & $45 / 51$ & 1.58 & 4.92 & 2.83 & 0.58 & 23.07 & 0.47 & 9.02 & 4.57 & 0.51 & 23.14 \\
Cluster 8 & $43 / 26$ & 1.55 & 5.44 & 4.37 & 0.80 & 26.91 & 0.77 & 6.71 & 4.89 & 0.73 & 19.96 \\
Cluster 9 & $13 / 31$ & 2.26 & 0.98 & 0.98 & 1.00 & 17.62 & 0.96 & 3.43 & 2.02 & 0.59 & 12.87 \\
Cluster 10 & $27 / 25$ & 1.73 & 1.44 & 1.54 & 1.07 & 18.07 & 0.84 & 2.61 & 1.73 & 0.66 & 12.36 \\
\hline
\end{tabular}

Table 2: Mean chloride, nitrate, sulphate, and $\mathrm{PM}_{10}$ concentrations by trajectory cluster for winter and spring at Belfast and Harwell, in $\mu \mathrm{g} \mathrm{m}^{-3}$

\begin{tabular}{|c|c|c|c|c|c|c|c|c|c|}
\hline \multirow[b]{2}{*}{ Aerosol } & \multirow[b]{2}{*}{$\mathrm{N}$} & \multicolumn{3}{|l|}{ Winter } & & \multicolumn{3}{|l|}{ Spring } & \multirow[b]{2}{*}{$\mathrm{PM}_{10}$} \\
\hline & & Chloride & Nitrate & Sulphate & $\mathrm{PM}_{10}$ & Chloride & Nitrate & Sulphate & \\
\hline \multicolumn{10}{|l|}{ Belfast } \\
\hline Cluster 1 & $18 / 33$ & 2.89 & 2.02 & 1.70 & 18.67 & 2.34 & 1.25 & 2.01 & 16.64 \\
\hline Cluster 2 & $44 / 41$ & 3.33 & 1.14 & 1.48 & 15.39 & 2.44 & 0.78 & 1.52 & 14.85 \\
\hline Cluster 3 & $35 / 34$ & 2.50 & 1.40 & 1.75 & 14.71 & 1.79 & 4.48 & 3.44 & 19.85 \\
\hline Cluster 4 & $16 / 18$ & 2.78 & 7.94 & 5.27 & 34.44 & 1.46 & 8.79 & 5.27 & 30.61 \\
\hline Cluster 5 & $14 / 17$ & 2.88 & 1.49 & 1.72 & 23.36 & 1.71 & 5.87 & 2.37 & 20.71 \\
\hline \multicolumn{10}{|l|}{ Harwell } \\
\hline Cluster 1 & $09 / 25$ & 1.47 & 2.47 & 1.06 & 11.33 & 1.32 & 1.76 & 1.46 & 10.40 \\
\hline Cluster 2 & $26 / 45$ & 2.64 & 1.17 & 1.28 & 10.15 & 1.45 & 1.57 & 1.61 & 10.56 \\
\hline Cluster 3 & $26 / 22$ & 1.63 & 2.13 & 1.88 & 11.92 & 0.56 & 4.41 & 2.81 & 12.27 \\
\hline Cluster 4 & $12 / 26$ & 1.12 & 6.86 & 4.42 & 17.92 & 0.40 & 11.04 & 6.45 & 25.19 \\
\hline Cluster 5 & $10 / 12$ & 1.14 & 4.68 & 2.78 & 13.70 & 0.89 & 6.27 & 3.12 & 16.58 \\
\hline
\end{tabular}

Table 3: Mean chloride, nitrate, sulphate, and $\mathbf{P M}_{10}$ concentrations by trajectory cluster for summer and autumn at Belfast and Harwell, in $\mu \mathrm{g} \mathrm{m}^{-3}$

\begin{tabular}{|c|c|c|c|c|c|c|c|c|c|}
\hline \multirow[b]{2}{*}{ Aerosol } & \multirow[b]{2}{*}{$\mathrm{N}$} & \multicolumn{3}{|l|}{ Summer } & \multirow[b]{2}{*}{$\mathrm{PM}_{10}$} & \multicolumn{3}{|l|}{ Autumn } & \multirow[b]{2}{*}{$\mathrm{PM}_{10}$} \\
\hline & & Chloride & Nitrate & Sulphate & & Chloride & Nitrate & Sulphate & \\
\hline \multicolumn{10}{|l|}{ Belfast } \\
\hline Cluster 1 & $45 / 25$ & 1.60 & 1.38 & 1.34 & 13.00 & 1.30 & 1.71 & 1.33 & 16.92 \\
\hline Cluster 2 & 49/33 & 1.24 & 0.99 & 1.15 & 10.63 & 2.36 & 1.37 & 0.81 & 15.97 \\
\hline Cluster 3 & $37 / 36$ & 0.73 & 2.08 & 1.74 & 13.11 & 1.70 & 2.26 & 1.40 & 16.64 \\
\hline Cluster 4 & $22 / 32$ & 0.49 & 3.86 & 2.63 & 18.59 & 0.94 & 4.31 & 3.20 & 23.50 \\
\hline Cluster 5 & $14 / 15$ & 1.01 & 2.09 & 2.11 & 16.64 & 1.31 & 2.88 & 2.49 & 19.33 \\
\hline \multicolumn{10}{|l|}{ Harwell } \\
\hline Cluster 1 & $30 / 20$ & 0.23 & 1.81 & 1.88 & 13.33 & 1.06 & 2.20 & 1.87 & 12.05 \\
\hline Cluster 2 & $36 / 30$ & 0.74 & 1.83 & 1.53 & 11.50 & 1.89 & 1.62 & 1.45 & 10.93 \\
\hline Cluster 3 & $37 / 30$ & 0.24 & 1.63 & 1.94 & 12.22 & 0.86 & 4.06 & 2.43 & 14.10 \\
\hline Cluster 4 & $30 / 16$ & 0.09 & 5.89 & 3.05 & 23.20 & 0.60 & 5.36 & 4.45 & 17.31 \\
\hline Cluster 5 & $16 / 14$ & 0.35 & 2.13 & 1.43 & 13.56 & 0.80 & 2.89 & 3.12 & 13.57 \\
\hline
\end{tabular}


Table 4: The $10^{\text {th }}$ and $90^{\text {th }}$ percentiles by trajectory cluster for the whole data set 2002-2003 at Belfast and Harwell

\begin{tabular}{|c|c|c|c|c|c|c|c|c|c|}
\hline \multirow[b]{3}{*}{ Aerosol } & \multicolumn{9}{|c|}{ Percentiles } \\
\hline & \multicolumn{3}{|c|}{ Chloride } & \multirow{2}{*}{$\frac{\text { Nitrate }}{10 \text { th }}$} & \multirow[b]{2}{*}{ 90th } & \multicolumn{2}{|c|}{ Sulphate } & \multirow{2}{*}{$\frac{\mathrm{PM}_{10}}{10 \mathrm{th}}$} & \multirow[b]{2}{*}{ 90th } \\
\hline & $\mathrm{N}$ & 10th & 90th & & & 10th & 90th & & \\
\hline \multicolumn{10}{|l|}{ Belfast } \\
\hline Cluster 1 & 93 & 0.32 & 3.496 & 0.304 & 3.194 & 0.29 & 2.984 & 7 & 23.6 \\
\hline Cluster 2 & 103 & 0.484 & 4.114 & 0.33 & 3.278 & 0.304 & 3.316 & 7.4 & 23.6 \\
\hline Cluster 3 & 75 & 1.02 & 5.174 & 0.186 & 2.228 & 0.536 & 1.894 & 8.6 & 28.4 \\
\hline Cluster 4 & 60 & 0.44 & 5.074 & 0.28 & 2.016 & 0.431 & 2.48 & 6.1 & 19 \\
\hline Cluster 5 & 69 & 0.19 & 3.42 & 0.37 & 4.29 & 0.44 & 3.47 & 8 & 23 \\
\hline Cluster 6 & 50 & 0.161 & 2.726 & 1.058 & 18.083 & 1.533 & 6.731 & 10 & 43.9 \\
\hline Cluster 7 & 45 & 0.238 & 3.782 & 0.342 & 11.638 & 0.596 & 5.668 & 8 & 39.6 \\
\hline Cluster 8 & 43 & 0.304 & 3.334 & 0.582 & 12.818 & 0.896 & 7.758 & 10.4 & 43.6 \\
\hline Cluster 9 & 13 & 1.04 & 3.644 & 0.132 & 3.424 & 0.156 & 2.432 & 7.4 & 43.2 \\
\hline Cluster 10 & 27 & 0.45 & 3.488 & 0.254 & 3.488 & 0.34 & 3.85 & 8.8 & 30.6 \\
\hline \multicolumn{10}{|l|}{ Harwell } \\
\hline Cluster 1 & 34 & 0.2 & 2.6 & 0.54 & 2.36 & 0.715 & 2.515 & 7 & 13 \\
\hline Cluster 2 & 90 & 0.11 & 2.036 & 0.5 & 4.353 & 0.732 & 3.394 & 6.1 & 17 \\
\hline Cluster 3 & 60 & 0.582 & 4.512 & 0.333 & 2.517 & 0.525 & 2.811 & 7 & 15.9 \\
\hline Cluster 4 & 57 & 0.028 & 2.688 & 0.386 & 3.684 & 0.572 & 3.688 & 7 & 17.2 \\
\hline Cluster 5 & 30 & 0.05 & 2.391 & 0.493 & 10.081 & 0.836 & 4.368 & 6 & 29.6 \\
\hline Cluster 6 & 68 & 0.03 & 0.951 & 0.698 & 6.42 & 0.862 & 4.812 & 9 & 21 \\
\hline Cluster 7 & 51 & 0.03 & 1.156 & 1.782 & 20.894 & 1.202 & 8.784 & 12 & 35.8 \\
\hline Cluster 8 & 26 & 0.154 & 1.53 & 1.562 & 13.542 & 1.107 & 8.517 & 10.4 & 32 \\
\hline Cluster 9 & 31 & 0.064 & 2.584 & 0.68 & 8.148 & 0.562 & 4.318 & 9 & 19.6 \\
\hline Cluster 10 & 25 & 0.132 & 1.776 & 0.574 & 5.264 & 0.402 & 3.26 & 8 & 17.4 \\
\hline
\end{tabular}



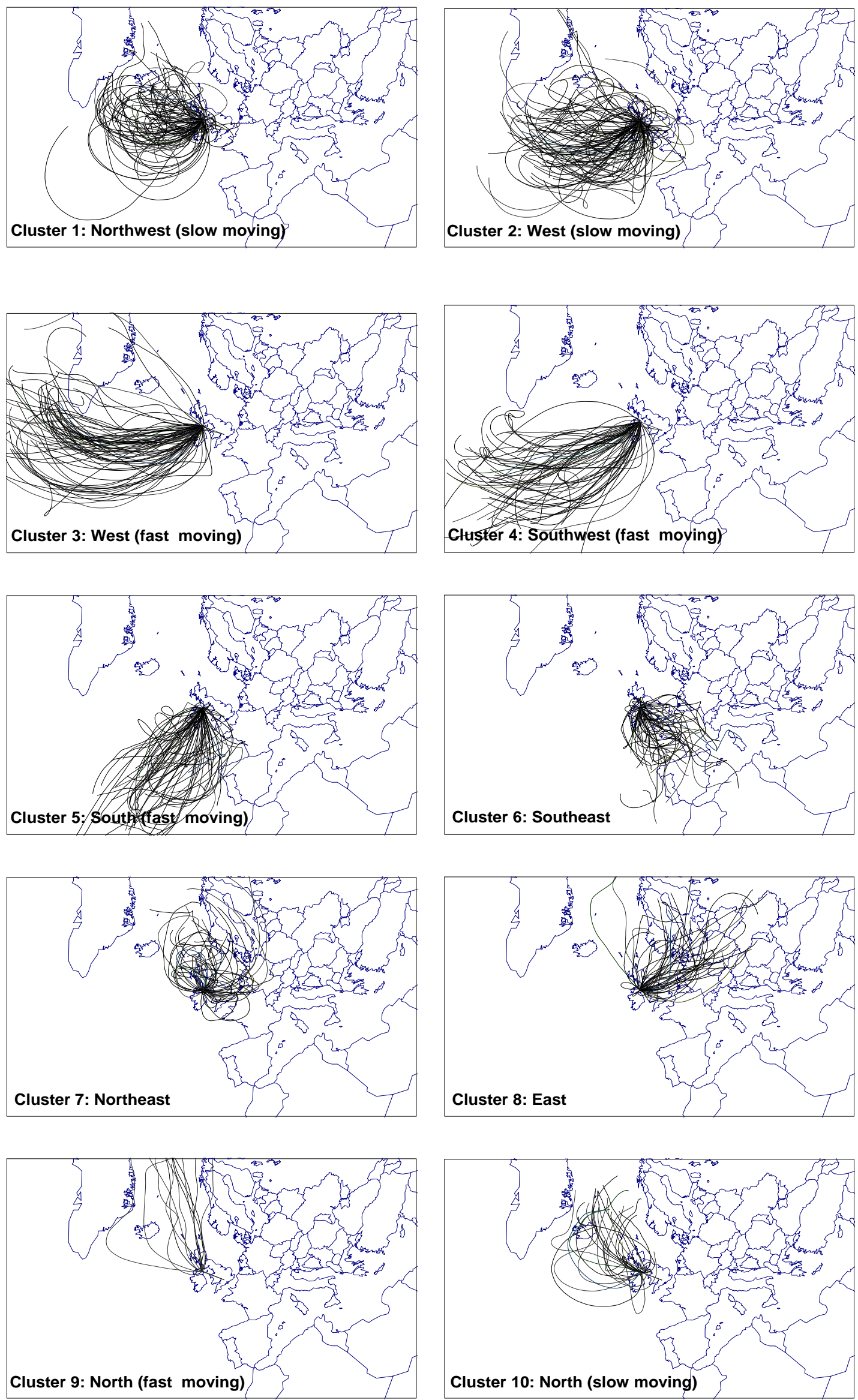

Figure 1: Three-day back trajectories arriving in Belfast at $1200 \mathrm{GMT}$ and $950 \mathrm{hPa}$ for 2002-2003 

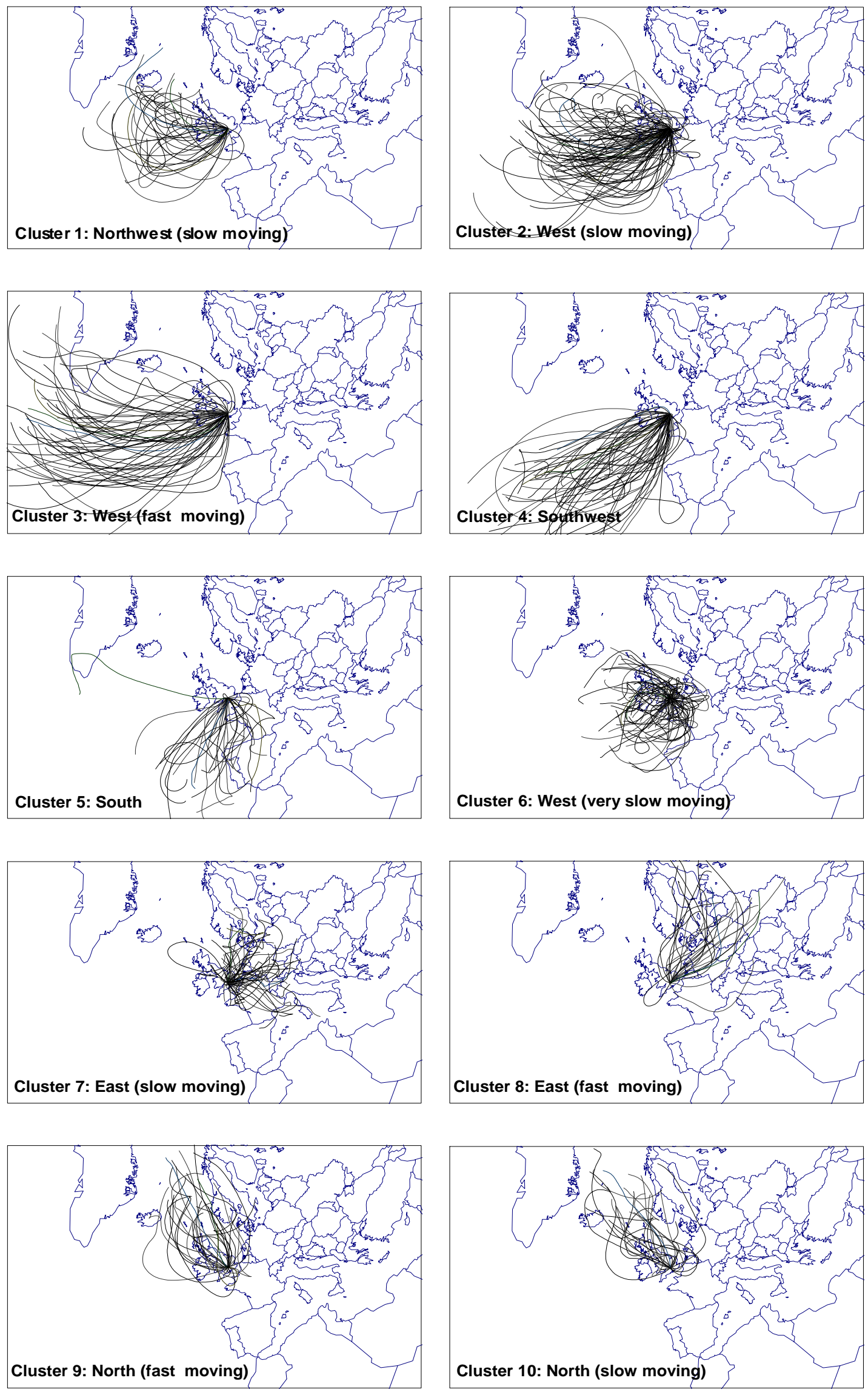

Figure 2: Three-day back trajectories arriving in Harwell at 1200 GMT and 950 hPa for 2002-2003 

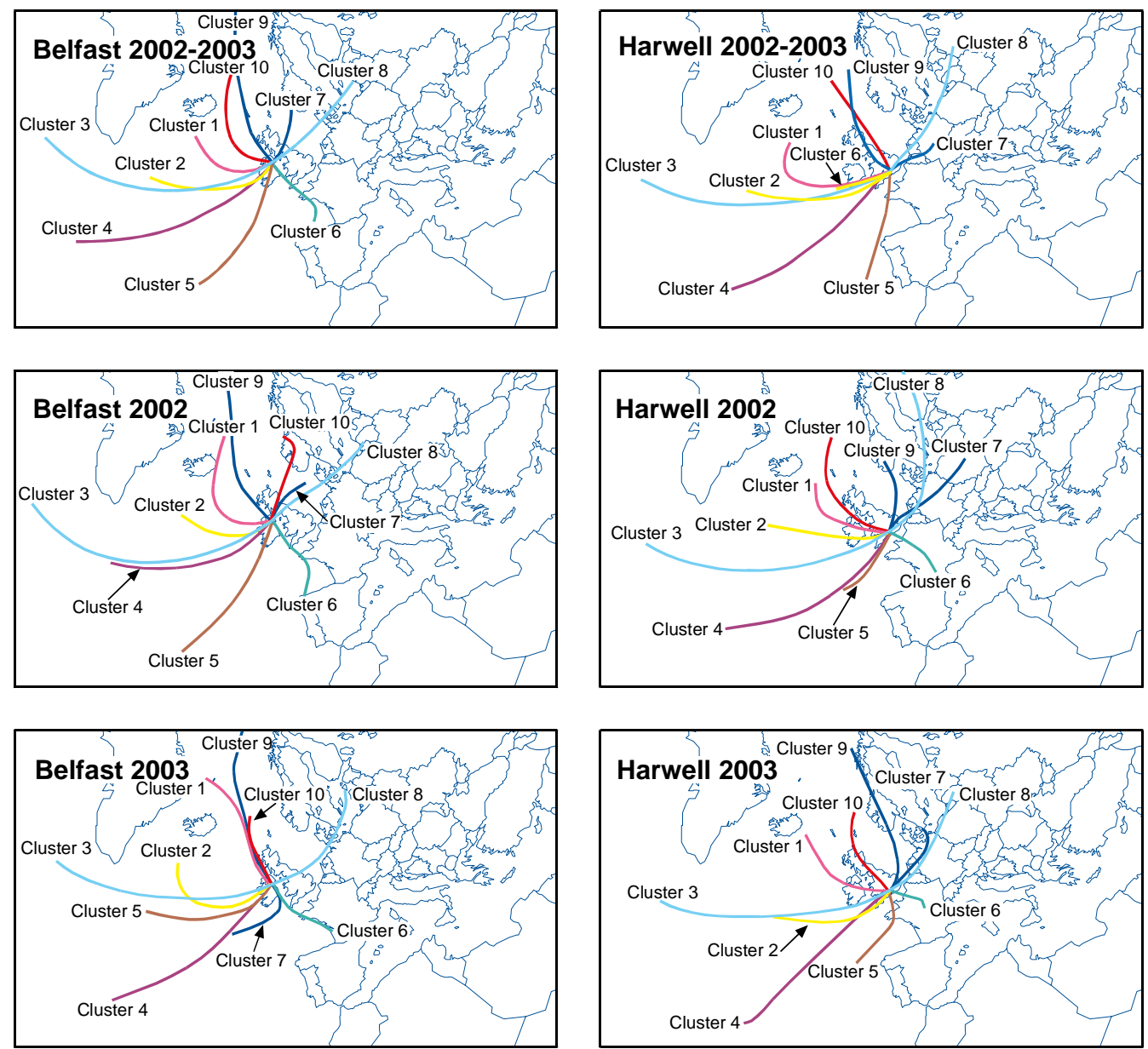

Figure 3: Mean three-day back trajectory for the main trajectory clusters at Belfast and Harwell for 2002-2003 
Harwell 2002-2003

Belfast 2002-2003

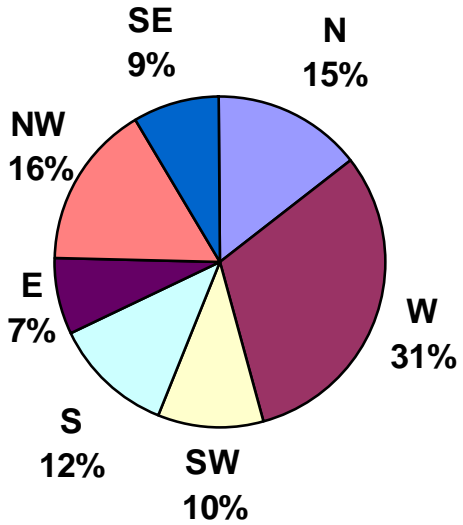

Belfast 2002

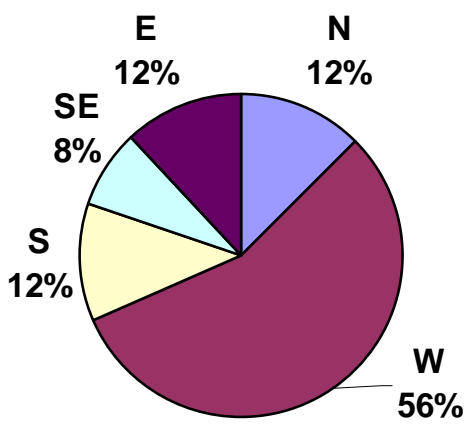

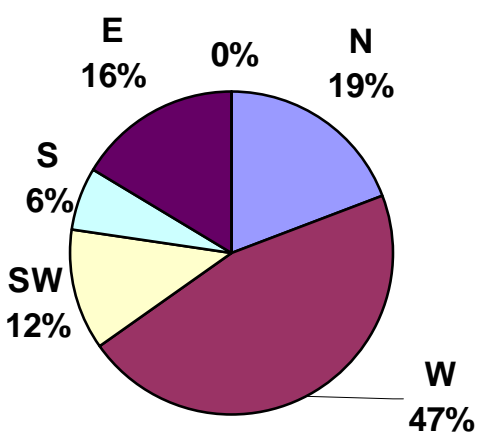

Belfast 2003

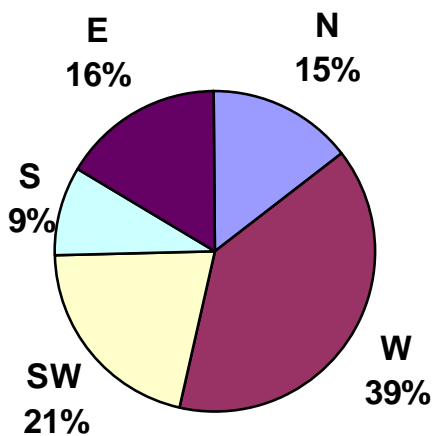

Harwell 2003

W.

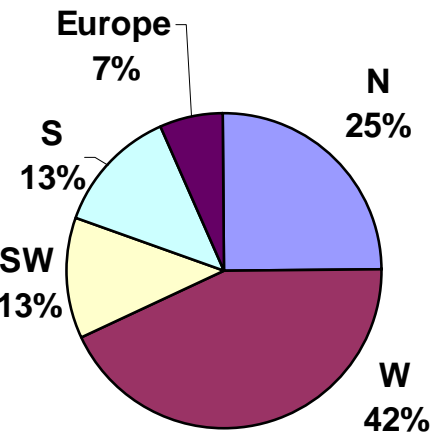

Figure 4: Distribution of back trajectories across the main clusters for the years 2002, 2003 and the whole data set 2002-2003 analysed separately 

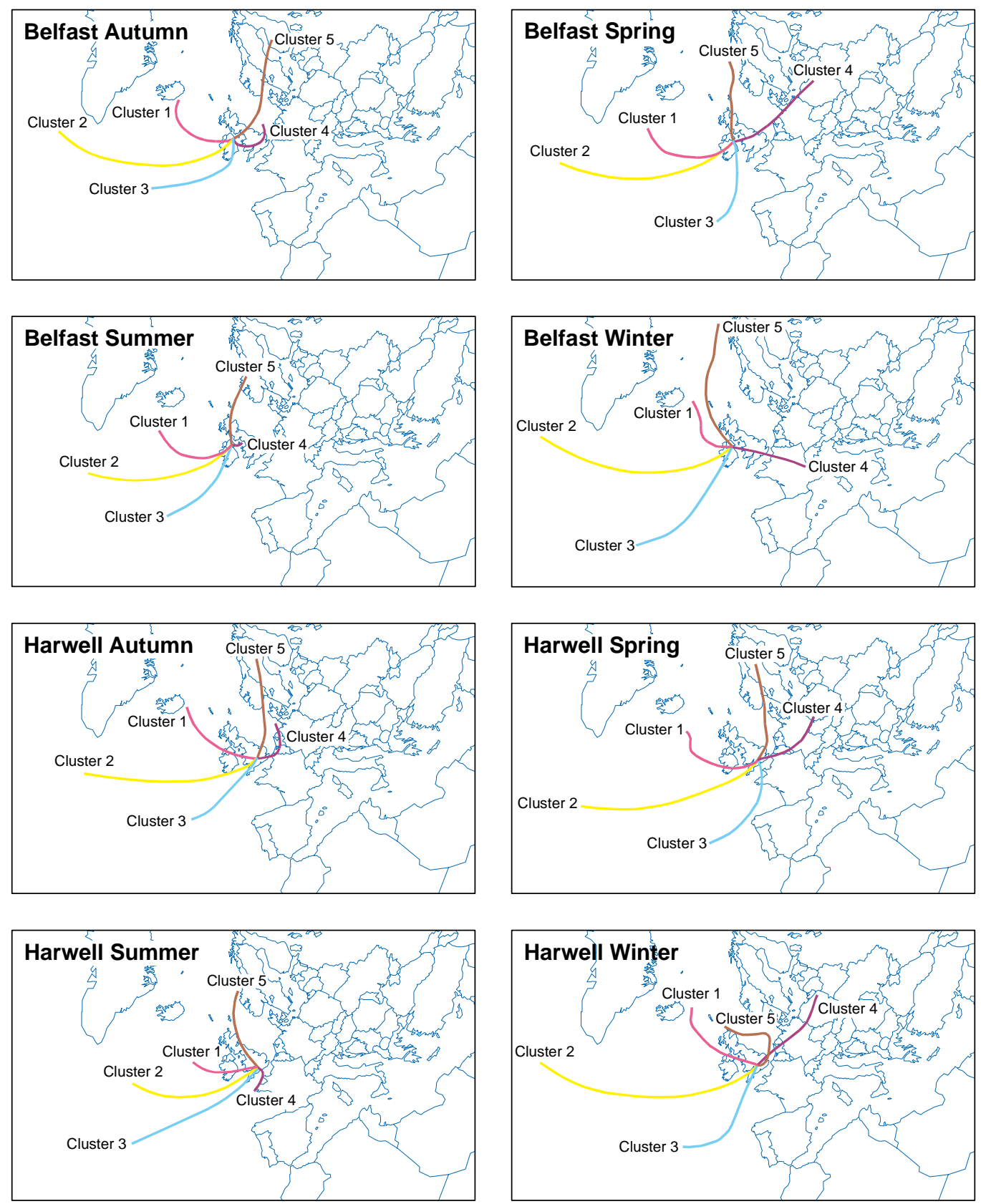

Figure 5: Mean three-day back trajectory for the main clusters in each season at Belfast and Harwell for 20022003 